\title{
Spatial Development Process of the Turkish Historical Dwelings (Houses) and Interior Specifications
}

\author{
Salih Salbacak \\ Fatih Sultan Mehmet Vakif University, Faculty of Architecture and Design, \\ Interior Architecture Department, Istanbul, Turkey \\ E-mail: ssalbacak@fsm.edu.tr
}

\begin{abstract}
With the start of the history of civilization, the need for shelter occurred, people living in temporary and primitive shelters started to live in open areas with the improvement of climatic conditions, and with the formation of the settled order, architectural habitats began to form and common living spaces began to form. In the light of the researches, Anatolia has been inhabited intensively since the Paleolithic period, with the first settled order and many civilizations, it came under the sovereignty of the Byzantine and later Turks and had a rich cultural and architectural accumulation. It is known that Turks lived a nomadic life before settling in Anatolia and lived in easily established and detachable living environments that can produce solutions for different climates such as summer and winter.

In this study, the spatial breaks that emerged as a result of the meeting of Central Asian nomadic life culture with Anatolian cultures are examined through physical and cultural references, and the development of the residential architecture, which is a product of Anatolian design heritage, with the main lines of the traditional Turkish house, and the interior space in these traditional houses, its setup and hardware are documented.
\end{abstract}

Keywords: Anatolia, The Turkish Historical Dwellings (House), material culture, cultural heritage, interior space

DOI: $10.7176 / J S T R / 6-07-14$

\section{Geleneksel Türk Evinin Mekânsal Gelişimi ve İç Mekân Özellikleri}

Özet

Uygarlık tarihinin başlaması ile birlikte barınma ihtiyacı oluşmuş, geçici ve ilkel barınaklarda yaşayan insanlar iklim koşullarının iyileşmesi ile açık alanlarda yaşamaya başlayarak yerleşik düzene geçmiş, yerleşik düzenin oluşması ile de mimari şekillenerek ortak yaşam alanları oluşmaya başlamıştır. Yapılan araştırmalar 1şı̆̆ında Anadolu, paleolitik dönemden beri yoğun bir şekilde iskân edilmiş, ilk yerleşik düzen ve birçok medeniyet görülerek Bizans ve daha sonrasında Türklerin egemenliğine girerek zengin bir kültürel ve mimari birikime sahip oluşmuştur. Türklerin Anadolu ya yerleşmeden önce göçebe bir yaşam sürdüğü, yazlık ve kışlık gibi farklı iklime göre çözüm üretebilen kolay kurulan ve sökülebilen yaşam çevrelerinde yaşadıkları bilinmektedir.

Bu çalışmada Orta Asya göçebe yaşam kültürünün Anadolu kültürleri ile tanışması sonucu ortaya çıkan mekânsal kırılmalar fiziksel ve kültürel referanslar üzerinden irdelenerek Anadolu tasarım mirasının bir ürünü konut mimarisinin, 2000 yıllık ana hatları ile gelişimi ve geleneksel Türk evi kavramının temelleri incelenerek bu geleneksel evlerdeki iç mekân kurgusu ve donanımı belgelemektir.

Anahtar Kelimeler: Anadolu, geleneksel Türk evi, maddi kültür, kültürel miras, iç mekân.

\section{Giriş}

Yerleşme ve yapılı çevre uygarlık tarihi ile eşzamanlı gelişim gösterir ve insan yeryüzünde yaşamaya başladığı zaman diliminden günümüze temel gereksinimleri için doğa ile mücadele eder. Barınma da bu temel gereksinimlerden biri olarak bu eyleminin gerçekleşeceği fiziksel çevre koşullarına karşın üretilen dış çeper, (kabuk) mimarinin, dış etkilerden yalıtılan ve kullanıcı isteklerine göre programlandırılan 
yaşam çevreleri ile de iç mimarinin temelleri atılır. Yeryüzü parçasının konumu, nitelikleri ve kültürel öğelerinden referans alan yerleşim birimleri, maddi kültür alanlarını ifade eder, iki kıtanın birleşim noktasında yer alan ve Anadolu olarak adlandırılan günümüz Türkiye Cumhuriyeti sınırları da bu maddi kültür alanlarından birisidir. Yerleşim ve yapılaşmanın tarih öncesi dönemlerden beri kesintisiz sürdüğü Anadolu toprakları, kıtaların olduğu kadar kültürlerin de geçiş ve kesişim alanıdır. Geçmişin tüm belleğini ve izlerini barındıran Anadolu çok kültürlü ve dinamik bir kültür mozaiğine sahiptir. Elbette ki bu renklilik yerleşim kültürü ve iç mimari geleneğin gelişiminde de etkili bir öğedir. Geleneksel mimarinin çeşitlendiği bu coğrafyanın kuzeyi, güneyi, doğusu, batısı ve orta (çekirfek) kesimlerinde yapım sistemleri bakımından farklıklar gösteren yerleşme alanları bulunsa da yaratılan ve sürdürülen ortak kültürel ögeler, üretim biçimi, dini inanışlar ve estetik değerler mimariye ve iç mekân örgütlenmesine referans vermektedir.

\section{Anadoluda Konut Mimarisinin Gelişimi}

Anadoluda yerleşmenin tarihi Paleolitik döneme kadar uzanır. Bu dönemde Anadolunun farklı bölgelerinde düz yerlerdeki yerleşimlerin yanı sıra, nehir sekilerindeki yerleşmeler ile iskân edilmiş mağaralar ve kaya sığınakları görülmüştür, bu merkezlerin en önemlileri arasında Karain, Belbaşı, Beldibi, Öküzini gibi mağaralar yer alır (Sinemoğlu, 1984:422). İklimsel koşulların değişmesi ile tarımsal üretimin başladığı neolitik döneme gelindiğinde, Anadolu, dünyadaki en ileri yerleşimlere sahiptir. Özellikle bu dönem yerleşimlerinden Çatalhöyük, dünyadaki en eski köy kültürünü yansıtan önemli bir yerleşme olarak dikkati çekmektedir (Akurgal 1993). Çatalhöyük Köyü, üretimin ve kolektif köy yaşantısının bütün gereklerinin yerine getirildiği bir yerleşmedir. Köyde gündelik yaşama göre biçimlenen ve sınırlarını iç mekânın belirlediği birimlerden eklemlenerek çoğalan, bitişik nizamlı, düz damlı bir yapılaşma görülmektedir. Günümüz işlevlerinin bulunduğu iç mekân oldukça fonksiyoneldir, gündelik gereksinimlerin yansıra inanışların da duvar resimleri ile yansıdığ 1 bu konutlarda kapı, pencere bulunmaması sebebiyle dam üzerinden işleyen giriş sistemi ve damın gündelik yaşama dahil edildiği bir kullanım görülmektedir (Şekil 1).

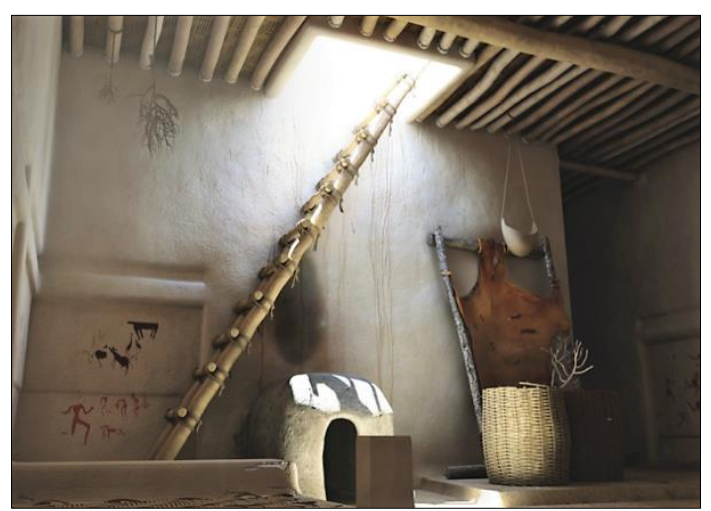

Şekil 1. Eve girişi yolunu ve ocağın merdiven altındaki pozisyonunu gösteren üç boyutlu modelleme.

(Modelleme: Grant Cox) http://www.catalhoyuk.com/tr

Bakır çağında, mevcut tarım toplulukları merkezileşmiş ve konutlar tekilleşmeye başlamıştır. Bunun sonucu yaşamın odağı giderek düz damlardan avlulara kaymış, günümüze kadar ulaşacak olan avlulu konut geleneği ortaya çıkmıştır. Konut mimarisinde ortaya çıkan bir diğer değişiklik ise alt katta hayvancılık ve depolama, üst katta yaşama faaliyetlerine dönük iki katlı kullanımdır (Esin, 1996). Tunç çağına ait bilgiler, Alacahöyük kazılarında ortaya çıkarılan küçüklü büyüklü yerleşim yerleri, bu çağ insanlarının, etrafı surlarla çevrili şehirlerde oturduğunu göstermektedir. Geleneksel Anadolu mimarisini temsil eden taş temelli, kerpiç duvarlı evler, dörtgen veya düzgün olmayan dikdörtgen odalı olup bu odalarda ocak, firın ve sedir bulunmaktadır (Anadolu Uygarlıkları Görsel Anadolu Tarihi Ans. 1982). Anadolu merkezli bir krallık olan Hitit devletinde, sivil mimari hakkında Anadolu Medeniyetleri Müzesinden öğrendiğimiz bilgilerde: Evlerin çoğunluğu tek katlı, temellerde taş, duvarlarda kerpiç, damlarında toprakla kaplı olduğunu eğer evlerin üst katları varsa, alt katın samanlık, ahır ve işlik olarak kullanıldığını, üst katın ise asıl yaşanan yer için ayılmış olduğunu öğrenmekteyiz.

Bir diğer Anadolu krallığı Friglerde (M.Ö. 750-300) mezar mimarisinde gelişme kaydedildiği, evlerin ise Hititlerinkine benzediği görülmüştür (Cezar, 1977:522). Doğu Anadoluda hüküm süren Urartular kayalık tepelere şehirlerini kurmuş ve ayrıca sağlam kale ve surlar ile güçlendirmişlerdir. Mimarlık 
alanında ve özellikle maden işçiliğinde çok yüksek düzeyde bir sanat ortaya koymuşlar, kayaların doruklarına araziye uydurmakta büyük beceri gösterdikleri tapınaklar ve saraylar inşa etmişlerdir (Sinemoğlu, 1984). Batı Anadoluda hüküm süren Lidyalıların başkentleri Sardesteki evlerin genel nitelikleri ise evler birbirine bitişik düzendedir ve bazen avluya benzer açık bir alana açılırlar. 1 ya da 2 odalı olan evlerin iç düzenlerinde ocaklar, depolama çukuru ve çöp çukurları en önemli öğeleri oluştururlar (Akurgal, 2002). Tunç devrinin sona ermesi ile Mezopotamya uygarlığı olan Asurlular Anadoluda ticaret kolonileri oluşturarak karum adını verdikleri pazarları, Persler de ticareti geliştirerek ünlü kral yolunu kurmuşlardır. Makedonyalı Büyük İskenderin, Pers egemenliğine son vermesi ile Anadoluda Helenistik dönem başlar. Bu dönem evlerinde de Prienede avlulu evler ön safta gelmekte, avluya açılan ve oradan hava ve sşık alan mekânlar arasında cephesinde anteler arasında iki sütun kapsayan bir ön mekâna (prostas) sahip megaron tarzında diğerlerinden daha büyük ve daha yüksek bir oda dikkati çekmektedir (Kuban, 1976:42). Helenistik dönemden sonrasında Anadoluda anitsal boyuttaki yerleşme ve yapıları ile dikkat çeken Roma dönemi başlar ve dönem evlerinde ise mekânlar avlunun çevresinde gelişen plan tipindedir.

Anadoluda farklı tarihlerde gerçekleşmiş Sasani, Hun ve Moğol istilaları kısa süreli olsa da bu istilaların yıkıcı etkisi oldukça büyük ve uzun süreli olmuş, insanlık tarihinin ilerleyişini ve antik çağın entelektüel gelişkinliğini durdurmuş, karanlık dönem olarak anılacak bir çağ başlamıştır. Hristiyanlığın doğuşu ile de mevcut entelektüel ortam ve yaşantı pratikleri temelinden sarsılmış, tapınaklar kiliseye dönüştürülmüş, tiyatrolar putperest kültlerle ilişkilendirilerek kapatılmış, hamamlar terk edilmiş, forumlar işlevsiz kalmıştır. Dönemin barınma alışkanlıkları çağın karmaşası sebebiyle fazla bilinmemekte, aydınlatıı yeterli kalıntı bulunmamaktadır. Daha çok yazıt ve erken edebi eserlerden, Konstantinopolis özelindeki konutlar aristokratik saraylar ve kolektif barınma blokları (insulae) ile örneklenebilir (Şekil 2). Diğer bir konut tipi olan aristokratik saraylar ise taş duvarları, tonoz tavanları ile oldukça gelişkin olup, antik çağa ait domus (Şekil 3). Olarak adlandırılan lüks konutlar ile benzerlik göstermektedir (Tanyeli, 1996). Yine Bizans döneminde Orta Anadoluda tek odalı basit evler kullanılmaktaydı. Bizans şehirlerinde büyük konakların planları zemin ya da birinci katta olan tricliium adı verilen büyük holün çevresinde organize edilmiş. Bu hol iki kat yüksekliğinde, genellikle çatıya kadar uzanmaktaydı. Erkeklerin kabul odası (divanhane) olarak kullanılırdı. Kadınların odaları yukarı katlardaydı büyük ve yüksek bir merkezi hol içeren büyük konutlara en iyi korunmuş örnek İstanbuldaki Blakernae Saray kompleksinin bir parçası olan Tekfur Sarayıdır (Kuban, 1995:25).
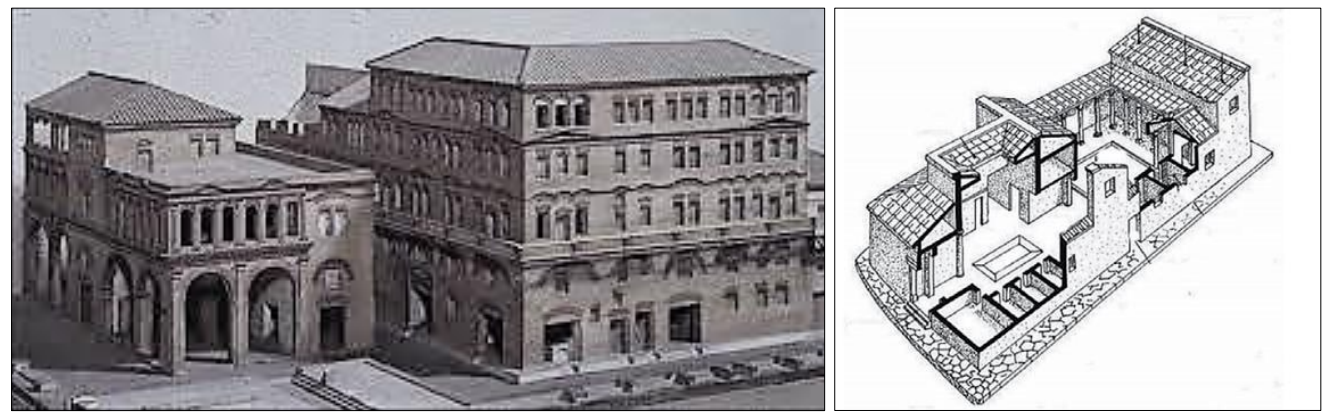

Şekil 2. Kolektif barınma blokları insulae. Şekil 3. Domus tipi konut. TRC1 Konut, TRC1 Bölgesi Tarihi, Teorik ve Ampirik Konut Değerlendirmesi İpekyolu Kalkınma Ajansı Araştırma Serisi- 7, s:16, Gaziantep, 2012.

Bütün bu gelişmelerin ışı̆̆ında XI. yüzyıla gelen Anadolu, 1071 Malazgirt meydan muharebesi ile Türk yurduna dönüşür. Orta Asyadan Anadoluya gelinceye değin birçok kültür ile tanışan Türkler bütün bu birikimlerini Anadoluya taşımış ve göçebeliğe dayanan Türk barınma kültürü, yerleşik düzenin hüküm sürdüğü Anadolu kültürleri ile etkileşerek Anadolu Türk konutu kavramı ortaya çıkmıştır. Türkler yerleşik düzenin yapım sistemleri ile göçebeliğin getirdiği barınma pratiğini birleştirirken yöresel malzeme, Türk töresi ve İslam inancının öğretilerini mekanlarına yansıtmışlar sivil mimari üzerinden gelişen bu süreç 1453de İstanbulun fethi ile imparatorluğa dönüşecek Osmanlı coğrafyasında sivil mimarinin yanı sıra anıtsal boyutlara ulaşan yapıları dünyaya miras bırakmışlardır.

\section{Geleneksel Türk Evi}

Anadoluya yerleşmeden önce Orta Asya steplerinde yaşayan Türklerin, yerleşim düzenleri göçebe özellikler göstermektedir. Tarım alanlarının elverişsizliği nedeni ile hayvancılıkla uğraşıp, yazın yaylalara çıkarak kışın kışlaklara inerek sürekli yer değiştiren Türklerin, yaşam çevreleri ise, taşınabilir 
evler yurt, alaçık ya da toprak ev olarak adlandırılan çadırlardır (Sözen, 2001:81). Bu çadırlarda: Ortada ateş yeri ya da korluk denilen ateş yakılacak yer bulunur soğuk havalarda burada ateş yakılır ve yemek de pişirilir. Çadır girişinin tam karşısına gelen ve tör denilen bölüm, genel olarak yük denilen sandıklar, hurçlar, keçe ve halıdan yapılmış bohçaların ve heybelerin dizildiği bir alandır (Küçükerman, 1985:53). Göçebeliğin getirdiği barınma düzeni esnek çözümler gerektirmektedir. Oturma, yemek pişirme ve yeme, dinlenme ve uyku, ibadet, depolama ve banyo gibi eylem ve işlevlerin bir arada kullanıldığı dairesel planlı çadırlar birden çok eylemin belirli mahremiyet koşulları ile sürdürüldüğü bir mekâna dönüşmüşlerdir. Ayrıca bu çadırların üst örtüsü ve iç donanımlarının tamamlayıcıları dokumalar, Türk kültürü ve sanatında gelişmiş özellikler gösteren ve aynı zamanda kültürel ve simgesel anlamlar da içeren halı, kilim ve dokumalar iç mekâna kimlik katarak geleneksel Türk iç mekanının gelişimini başlatırlar. Göçebe Türk toplumu, doğa ile bütünleşen ve onun bir parçası haline dönüşen bir yaşam sürdürmektedir. $\mathrm{Bu}$ nedenle yerleşik düzene geçerken oluşturulan mahalle ve kentlerde de bu düzen sürdürülmeye çalışılır. Gelenek, hukuk ve inanç sistemi ile şekillenen Türk aile yapısı aidiyet gerektirir, dinamiktir, süreklilik gösteren kurumsal bir yapıdadır ve hane halkı sayısına göre de sinıflandırılır. Şüphesiz ki yerleşik düzene geçerken bu geçiş aile üzerinden gerçekleşir, aileler mahalleleri, mahalleler de kentleri meydana getirir. Türk mahallesinde sınırları keskin hatlarla çizilemeyen arazinin topoğrafik yapısına göre konumlanan yerleşmeler cami ve etrafinda oluşan meydana odaklanır (Şekil 4). Meydan çevresindeki medrese ve çarşı dükkanları ise evler ile aynı alanda bulunmaz. Bu mahallelerde toplumun bütün katmalarına açık ve eşitlikçi bir yerleşim düzeni mevcuttur. İnşa edilen evler insan ölçeğindedir ve evlerin hacimsel boyutunu ailenin büyüklüğü belirler. İslam inancı gereği mahremiyet kavramının önemsendiği Türk mahallesinde bir ev diğerinin manzarası ve ışığını kesmemelidir (Şekil 5). Sınırları duvarlar ile belirlenmiş, içerisinde bitki ve ağaçlar bulunan iç avlular (Şekil 6) hem ailenin mahremiyetini sağlar hem de kadınların gündelik işlerini sürdürdüğü bir işlik olarak kullanılır. Geleneksel Türk evinin belirgin dış cephe özellikleri ise yapıların insan ölçeğinde olması, sokak ile kurduğu ilişki, cephe düzenindeki sadelik ve simetri, tepe pencereleri ve dişa çıkma yapan cumbalarıdır (Şekil 7).
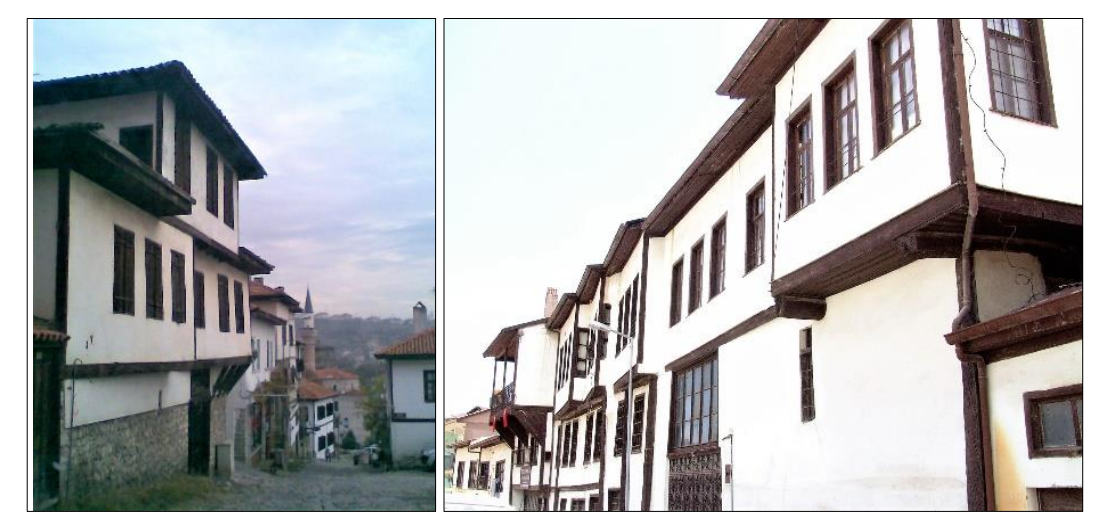

Şekil 4.Mahalle dokusu. Şekil 5. Türk mahallesinde evlerin dizilimi.
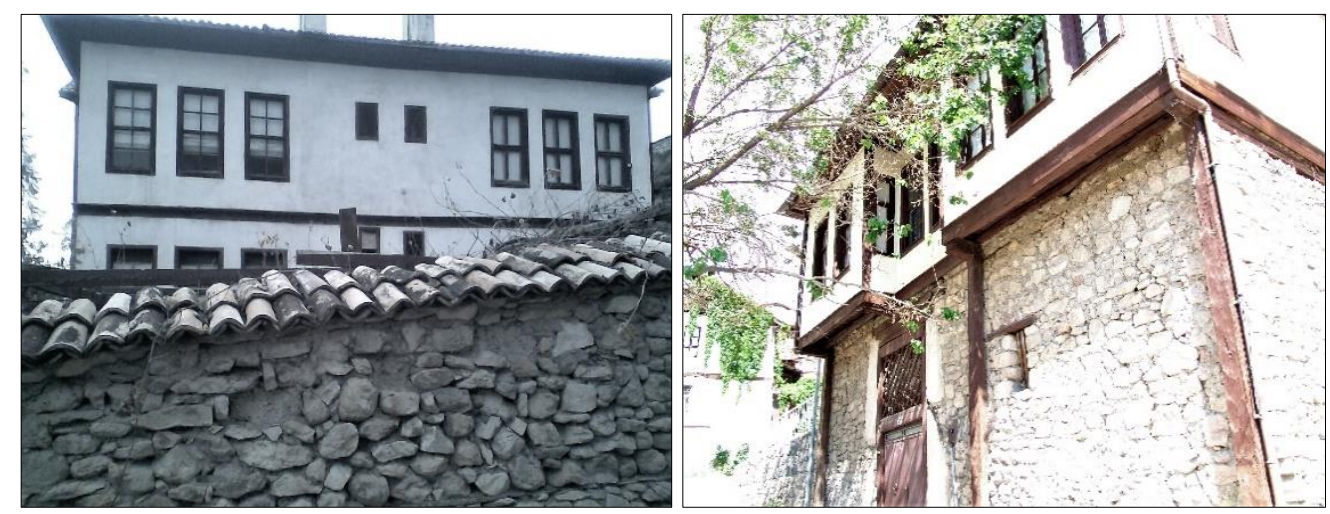

Şekil 6. Evlerin mahrem alanları. Şekil 7. Türk evinin önemli karakteristiklerinden çıkmalar. S. Salbacak kişisel fotoğraf arşivinden.

Bu çıkmalar, Türk evinin önemli karakteristiklerinden biridir. Çıkmalar fazlalaştıkça evin dış duvarı daha hareketli olup, daha fazla hava ve güneşten yararlanmak mümkün olmuştur (Eldem, 1984: 19). Evler genellikle iki katlıdır. Ancak, kaç katlı olursa olsun, esas kat daima tektir ve mutlaka en yukarıdadır. Üst 
kat en şerefli kattır ve plan bu kata göre yapılmıştır (Eldem, 1984: 16). Geleneksel Türk evi, geleneksel Türk ailesinin yaşam kültürü ve törenlerine uygun şekil ve plan özellikleri gösteren asırlarca Türk insanının gereksinimlerine cevap vermiş bir konut tipi olarak bilinmekte ve tanımlanmaktadır. Geleneksel Türk evinde gözlenebilen en ilginç ve sürekli özellik değişik bölgesel niteliklere karşın ortak bir motifin varlığıdır (Ünügür, 1992:149). Bazı kaynaklarda bu evler Türk evi yerine Osmanlı evi olarak da adlandırılmaktadır. Ancak Türk evi olarak adlandırılan bu evler, tarihte daha çok Türkmenlerin yerleştiği dağlık yörelerde yapılmış olmaları ve güçlü ortak özelliklere sahip olmaları nedeniyle, bu isim uygun görülmüştür. Ayrıca, Osmanlı döneminde birçok kentte Türk Mahallesi, Rum mahallesi, Yahudi mahallesi gibi mahalle bazında bir ayrımın olduğu dikkate alındığında, sözü geçen konutların Türk konut mimarlığının temsilcisi olduğu söylenebilir (Yürekli, 2007: 10). Türk evinde ana yapım malzemesi ahşap, yapım yöntemi de ahşap çatkıdır. Bu sistem geleneğin devamı olduğu kadar malzemenin kolay temini ve deprem gibi fiziksel faktörlerden de etkilenmiştir.

\subsection{Geleneksel Türk Evinde İç Mekân}

Geleneksel Türk evlerinin plan şemasını oluşturan en önemli birim oda ve odalar arası geçişi sağlayan sofadır. Sofa: sergah, sergi, eyvan, çardak, divanhane, hayat vb. isimler almıştır. Bu alan ev içindeki dolaşımı sağlamakla birlikte aynı zamanda bir toplanma alanıdır (Küçükerman, 1985:53). Sedat Hakkı Eldem Türk evi plan tiplerini, sofasız, dış sofalı, iç sofalı ve orta sofalı plan tipi olarak dört grupta (Şekil 8) tarif etmektedir. Bu plan tiplerini yine Eldeme göre özetlediğimizde: Sofasız Plan tipi, Anadolu Türk evinin ilk örneklerindendir ve orta, güney ve doğu bölgelerinde özellikle de kır ve yayla evlerinde uygulanır. Mekân organizasyonunda odalar bahçe duvarı ile çevrilen iç avluya açılır. Dış Sofalı Plan Tipinin oluşumunda iklim önemli bir faktördür ve bu plan tipine Ege ve Güney bölgelerimizde daha çok rastlanılır (Şekil 8). Mekân organizasyonunda da odalar dış bir sofaya açılır. İç Sofalı Plan Tipinde de odalar sofaya açılır (Şekil 8). Hacimsel esneklik sunan bu plan tipinde sofanın dört yanı aynı birimden odalar ile çevrelenir ve sofanın bir köşesine merdiven konumlandırılır. Orta Sofalı Plan Tipinde ise evin merkezinde ve dört tarafı oda ile çevrili iç sofalı tip ile benzerlik gösterirken daha çok İstanbulda büyük ve zengin evlerde uygulanır (Eldem, 1984). İlerleyen tarihsel süreçlerde form değiştiren örnekleri mevcuttur (Şekil 8).

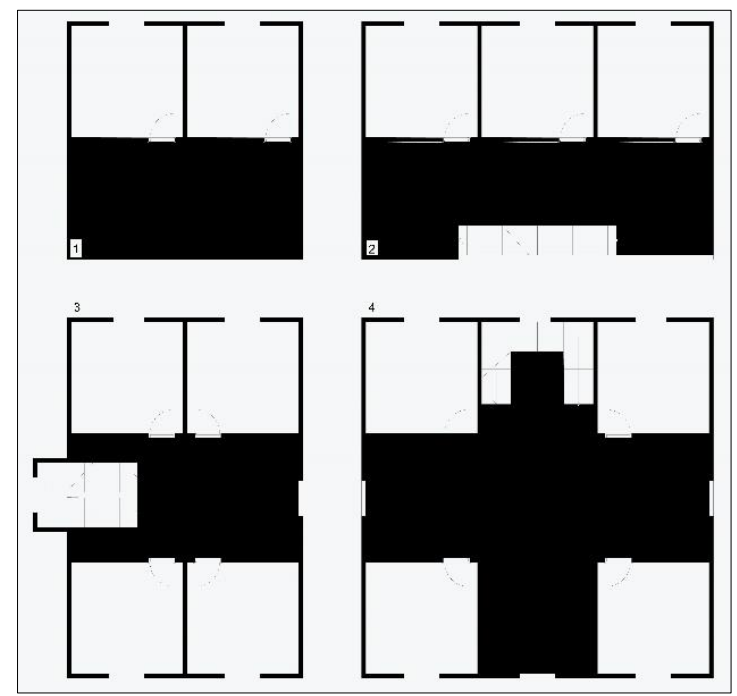

Şekil 8. 1.Sofasız, 2.Dış sofalı, 3. İç sofalı ve 4. Orta sofalı plan tipi olmak dört grupta incelediğimiz Türk evi plan tipleri. S. Salbacak kişisel arşivinden.

Türk evinin iç mekanını tanımlayan ve karakterize eden öğe odadır. Dikdörtgen formda bulunan ve çekirdek ailenin ihtiyaçlarını karşılayacak biçimde işlevlendirilen odada sedir, yüklük, ocak, gusülhane gibi bölümler bulunmaktadır. Odanın biçimlenmesinde ailenin sosyal ve ekonomik durumu ve aile içindeki hiyerarşik yapı öne çıkan unsurlardır. Bu sebeple de büyük evlerde haremlik, selamlık, divanhane ve baş oda adı verilen bölümler de bulunmaktadır.

Osmanlı odası erken dönem konutların ana bileşenidir. Oda ve otağ sözcüklerinin etimolojik benzerliği ile göçebeliğin konuttaki yansıması kabul edilen mobilyasızlık faktörü, kültürel köken ve ortaklık olarak açıklayıcıdır. Oda ve otağın diğer benzerliği yaşama, yeme ve yatma alışkanlıkları her iki bütüncül mekânda da kesintisiz bir şekilde sürdürülebilmesi, işlevsel ve esnek kullanım özelliklerine sahip 
olmasından kaynaklanmaktadır. Otağda ısınmak için kullanılan ocaklar merkezde iken Osmanlı odasındaki ocak duvarda yer alır. Orta Asya kullanımı ile farklılık gösteren ve Arap kültüründe bulunmayan bu mimari eleman Anadolu kültürünün bir parçası olduğu düşünülmektedir. Ocağın yanındaki karşılıklı duvarlarda zeminden $30 \mathrm{~cm}$ kadar yüksek oturma nişleri bulunur, bu doku bir mimari gelenek olarak günümüze kadar uzanacaktır (Tanyeli, 1996).

Geleneksel Türk odasının merkezinde ocak bulunur yangın tehlikesine karşı genelde taştan örülmüş bir duvar nişi içerisine konumlandırılır. Ocağın sağında ve solundaki taş duvara nişler açılarak bu nişlere odayı aydınlatan kandil ve Kur'an-1 Kerim konularak dekoratif öğe olarak kullanılır ve yine ocağın alın kısmı yöresine göre işlemeli veya sade örneklerinin sergilendiği görselleştirilmiş hali ile bulunmaktadır. İki ya da üç odalı plan tiplerinde mutfak hariç sadece baş odada ocak bulunmakla birlikte büyük evlerde bütün odalarda ocak bulunabilmektedir. Odanın oturma elemanı sedirdir (Şekil 10). Sedir, pencere önüne konumlanır ve cephe boyunca pencere ile paralel devam eden arkalıksız üstü minderli ve yastıklı sabit bir donatıdır. Göçebe çadırlarda kullanılan sergi ve yaygı dokumaları sedirlerde ve yastıklarda da kullanılırken ayrıca sedirler perdelerle birlikte uyum içerisinde evin kadınının işlediği bitki ve çiçek işlemeli örtülerle süslenir. İç mekânda kullanılan önemli elemanlardan birisi de yüklüklerdir. Yüklükler, gündüzleri yatakların kaldırılarak depolamanın sağlandığı duvar yüzeyine sabit dolaplardır (Şekil 11). Bu dolaplar yöresel özelliklere ve ailenin maddi durumuna göre kapakları işlemeli, desenli veya sade olabilmektedir. Odanın en süslü yüzeyi tavandır ve işçiliklerine göre iç mekân tarihine kaynak olabilecek üslupta süslenen örnekleri bulunmaktadır. Evde mutfak giriş katında kiler ile bağlantılı olarak taş zemin üzerindedir, ocağın etrafinda yerden yükselen mutfak raflarında kap kaçak depolanır. Yine Türk evinde ıslak hacim olan helâlar genelde evlerin dışında hâkim rüzgâr yönüne göre konumlandırılır, yıkanma eylemi ise odalarda bulunan gömme bir dolap görünümde olan (Şekil 12) gusülhaneler de gerçekleştirilmiştir.

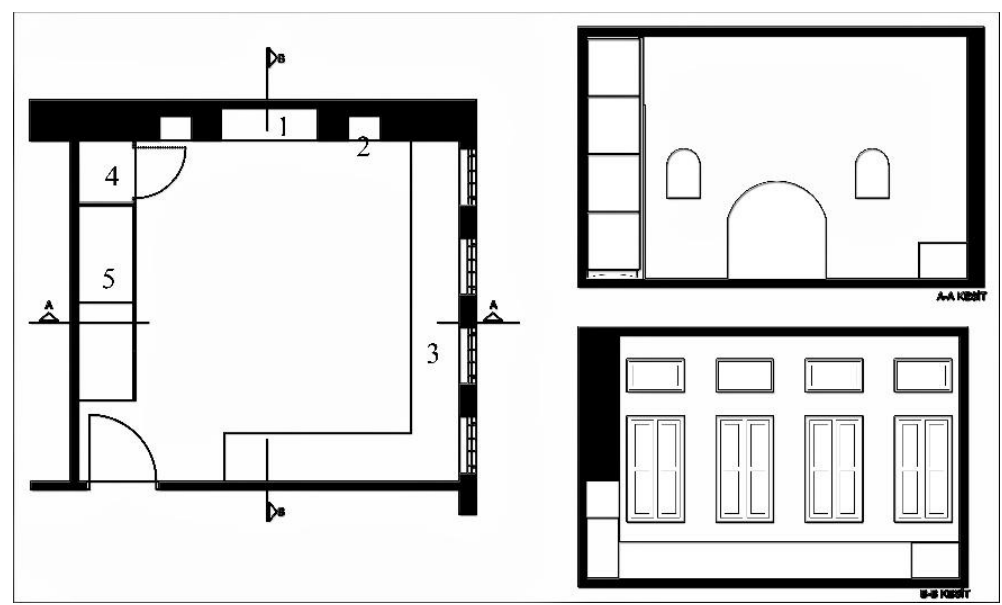

Şekil 9. Geleneksel Türk Odası 1. Ocak, 2. Dekoratif niş, 3. Oturma elamanı sedir, 4. Güsulhanre, 5. Yüklük A-A Kesit Ocağın görünümü B-B Kesit Sedir ve Tepe pencereleri.

S. Salbacak kişisel arşivinden.
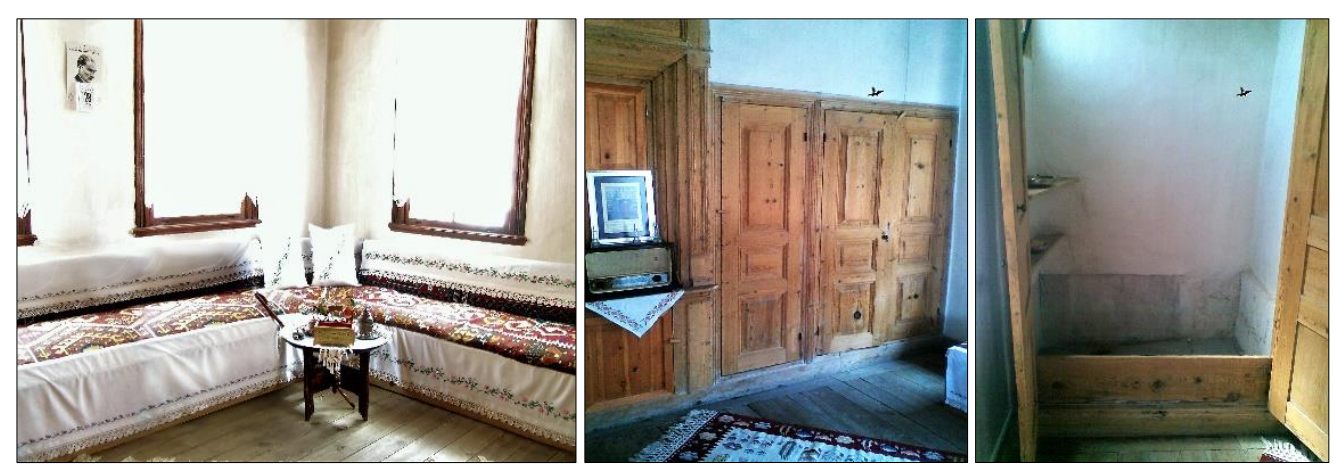

Şekil 10. Oturma bölümü sedir. Şekil 11. Depolama alanı yüklük. Şekil 12. Güsulhanre.

S. Salbacak kişisel fotoğraf arşivinden. 


\section{Sonuç}

Orta Asyadan Anadoluya göç ederken farklı kültürlerle tanışan ve etkileşen Türkler, Anadoluya geldiklerinde yerleşik düzen ve bu düzene uygun bir mimari ile karşılaşmış, göçebeliği yaylalarda sürdürürken kentlerde yerleşik düzene geçmişlerdir. Bu bağlamda yüzyılların birikimini barındıran Anadolu tasarım ve mimari mirasına, Orta Asya göçebe yaşam biçimini aktararak iki kültürün birleşimi Türk evi kavramını da eklemişlerdir. Bu evleri biçimlenişinde Anadolunun topografik yapısı ve bölgeler arasındaki iklimsel farklılıklar, sıcak iklim bölgelerinde açık sofalı, soğuk iklim bölgelerinde kalın taş duvarlı, küçük pencereli, iç sofalı, yönetim merkezi ve çevresinde ise orta sofalı plan tipolojilerini oluştururken ve büyük hacimli plan tiplerinin uygulanmasına olanak sağlayarak fiziksel etkenler, ailenin yapıs1, yaşam biçimi, ekonomisi, konuttan beklentileri ve estetik değerleri ile kültürel etkenler olarak rol oynamıştır.

Mahalle Türk yerleşim kültürünün önemli bir öğesidir. Ailelerin bir araya getirdiği mahalleler bireysel yaşantı yerine kolektif bilince, komşuluk ve dayanışma esasına dayanan alanlardır. Osmanlı gibi çok kültürlü bir toplumda mahalleler etnik ve dini farklılara göre ayrılmaktaydı Türk Mahallesinin merkezini cami, çarşı, hamam ve medrese gibi kamusal alanlar oluşturmakta idi.

Kültür konut ilişkisinin bir ürünü olan Türk evi ait olduğu kültürün özelliklerini taşıyarak kökenleri Orta Asya göçebe kültürüne kadar uzanır. Yerleşik düzene geçen Türk toplumunun konuttan beklentileri ve konutlarına yükledikleri anlamlar yine kültür konut ilişkisinin sürdürüldüğünü göstermektedir. Osmanlı coğrafyasının çok kültürlülüğü ile bir araya gelen yerleşme ve konut kültürü aile yapısı ile paralel gelişmiştir. 19. Yüzyıla gelinceye değin geleneğin sürdürüldüğü bilinmekle birlikte bu yüzyılda batılılaşma etkisi toplumun her alanında olduğu gibi mimarlık pratiğini de etkileyerek konutta bir kırılma yaratır. Yeni yapı ve konut düzenleri toplumsal hayata nüfus eder hatta bazı geniş ve varlıklı aileler geleneksel yaşam çevrelerinden uzaklaşarak batılılaşmanın merkezi semtlerde büyük aile apartmanları inşa ettirir ve taşınır. Konutta gelenekten kopuş tartışmaları cumhuriyet dönemi ile de sürer. Dönüşen Türk ailesinin barınacağı yeni konut arayışları devam eder ancak arayışlarda geleneksel Türk evinin referansları gözlenir.

Anadolu tasarım mirasının bir ürünü olan Türk evi günümüze kadar ulaşmıştır ve ait oldukları yörelerin dokusunu yansıtan yerleşim alanları ve konutlar bulunmakta ve yaşatılmaktadır. Toplulukların kültürel kimliklerinin bir parçası ve onları farklı kılarak yansıtan mimari ve iç mimari mirasımızın koruması için günümüzde çeşitli çalışmalar yapılmaktadır. Bu çalışmalar ile kültürel ve mekân kimliğinin sürekliliğinin sağlanması, korunması, tanıtılması ve geliştirilerek gelecek kuşaklara aktarılması amaçlanmalıdır.

\section{Kaynakça:}

Akurgal, E. (1993), Anadolu Uygarlıkları, Net Turistik Yayınları, 4. Baskı, İstanbul.

Akurgal, E. (1998), Anadolu Uygarlıkları, TÜBİTAK Yayınları, Ankara.

Anadolu Uygarlıkları Görsel Anadolu Tarihi Ansiklopedisi, (1982), c.1, s,12.13.15.20.60 Görsel Yayınları, İstanbul.

Cezar, M. (1977), Anadolu Öncesi Türklerde Şehir ve Mimarlık, Türkiye İş Bankası Kültür Yayınları Ankara Kültür Yayınları Sanat Dizisi, s. 28, 520, Ankara.

Eldem, H S. (1984), Türk Evi Osmanlı Dönemi, c1, s.17, İstanbul.

Esin, U. (1996), M.Ö 6. Binyıldan 3. Biny1l Sonuna Kadar Doğu ve Güneydoğu Anadolu'da Habitat, Anadolu'da Tarihöncesi Çağlardan Tunç Çăğ Sonuna Kadar Konut ve Yerleşme, Türkiye Ekonomik ve Toplumsal Tarih Vakfi, İstanbul.

Kuban, D. (1976), Sanat Tarihimizin Sorunları, Çağdaş Yayınları, s. 192, İstanbul.

Kuban, D. (1995), Hayatlı Türk Evi, Eren Yayıncılık, s. 29, 117 152.154, İstanbul.

Küçükerman, Ö. (1985), Kendi Mekânının Arayışı İçinde Türk Evi, T.T.O.K Yayınları, s. 26.53.63, İstanbul. 
Sinemoğlu, N. (1984), Sanat Tarihi-Tarih Öncesinden Bizansa, Mimar Sinan Üniversitesi Yayınları, Milli Eğitim Basımevi, s.422, İstanbul.

Sözen, M. (2001), Türklerde Ev Kültürü, Doğan Kitapçılık AŞ, s:31, 81, 85, 86, İstanbul.

Tanyeli, U. (1996), Anadolu'da Bizans, Osmanlı Öncesi ve Osmanlı Dönemlerinde Yerleşim ve Barınma Düzeni, Türkiye Ekonomik ve Toplumsal Tarih Vakfi, İstanbul.

TRC1 Konut, TRC1 Bölgesi Tarihi, Teorik ve Ampirik Konut Değerlendirmesi İpekyolu Kalkınma Ajansı Araştırma Serisi- 7, s:16, Gaziantep, 2012.

Ünügür, T, H., Ünügür, M. (1992), Gelenekten Geleceğe Evimiz Proje Yarışması, T.C Kültür Bakanlığı Güzel Sanatlar Genel Müdürlüğü, s.139, ISBN 975-17-0989-X, Ankara.

Yürekli, H., Yürekli, F. (2007), Türk Evi Gözlemler-Yorumlar, YEM Yayın, İstanbul.

http://www.catalhoyuk.com/tr/sit/mimari 